\title{
Booster Gold Beam Injection Efficiency and Beam Loss*
}

\author{
S.Y. Zhang and L.A. Ahrens \\ AGS Department, Brookhaven National Laboratory, Upton, NY, USA

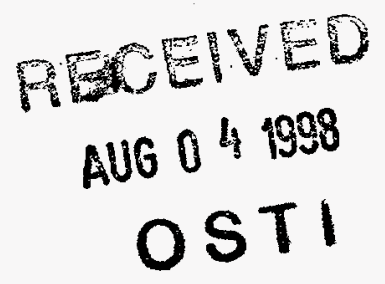

\section{Introduction}

The Relativistic Heavy Ion Collider (RHIC) at the $\mathrm{BNL}$ requires the AGS to provide Gold beam with the intensity of $10^{9}$ ions per bunch. Over the years, the Tandem Van de Graaff has provided steadily increasing intensity of gold ion beams to the AGS Booster. However, the gold beam injection efficiency at the Booster has been found to decrease with the rising intensity of injected beams. As the result, for Tandem beams of the highest intensity, the Booster late intensity is lower than with slightly lower intensity Tandem beam.

In this article, we present two experiments associated with the Booster injection efficiency and beam intensity. One experiment looks at the Booster injection efficiency by adjusting the Tandem beam intensity, and another looks at the beam life time while scraping the beam in the Booster. The studies suggest that the gold beam injection efficiency at the AGS Booster is related to the beam loss in the ring, rather than the intensity of injected beam or circulating beam.

A close look at the effect of the lost gold ion at the Booster injection leads to the prediction that the lost gold ion creates large number of positive ions, and even larger number of electrons. The lost gold beam is also expected to create large numbers of neutral particles. In 1998 heavy ion run, the production of positive ions and electrons due to the lost gold beam has been observed. Also the high vacuum pressure due to the beam loss, presumably because of the neutral particles it created, has been measured. These results will be reported elsewhere.

\section{Gold Beam Booster Injection}

The gold ion beam, $A u^{31+}$, is injected from the Tandem Van de Graaff to the AGS Booster with the kinetic energy of $E_{k}=0.9 \mathrm{MeV} / u$, i.e. $\beta=0.044$.

\footnotetext{
* Work performed under the auspices of the US Dept. of Energy
}

Up to 50 turns of beam can be injected, which takes about $750 \mu s$, to provide total up to $N=6 \times 10^{9} A u^{31+}$ ions. The multiturn injection stacks the turns into betatron space, both horizontal and vertical. After the RF capturing, it takes about $80 \mathrm{~ms}$ to accelerate the beam to $E_{k}=90 \mathrm{MeV} / u$. Then the gold ion beam is further stripped and transported to the AGS.

To accommodate the heavy ion injection, ultra high vacuum was designed for the Booster at $p=2 \times 10^{-11}$ Torr, which would lead to an $A u^{31+}$ beam life time of a few seconds at the injection energy. The beam life time observed in the machine is not only much shorter than that, but also depends on the intensity of injected beam. For example, for the injected beam intensity of $2 \times 10^{9}$ and $4 \times 10^{9}$ ions, the beam life time is a little more than $30 \mathrm{~ms}$ and $20 \mathrm{~ms}$, respectively, at the injection energy.

As a consequence, as the intensity of the injected beam increases to above $5 \times 10^{9}$ ions, the Booster late yield starts to decrease. This has been a problem in raising the AGS gold beam intensity to achieve the RHIC requirement.

To understand the beam loss mechanism, we performed two experiments, which will be described.

\section{Booster Injection Study}

In the first experiment [1,2], the Tandem beam intensity was set by using $3 \mu \mathrm{g} / \mathrm{cm}^{2}$ and $2 \mu \mathrm{g} / \mathrm{cm}^{2}$ terminal foils. For the latter, the intensity was further adjusted by inserting multiwires and reducing the rotary aperture. These cases are denoted by $A, B$, and $C$ in this article.

The Booster beam intensity are shown in Fig.1, where the stacking is started at about $0.1 \mathrm{~ms}$, and ended at $0.8 \mathrm{~ms}$. It can be observed that the beam life time after the stacking depends on the intensity. In the case $C$, the Tandem beam intensity as well as the stacked intensity are 


\section{DISCLAIMER}

This report was prepared as an account of work sponsored by an agency of the United States Government. Neither the United States Government nor any agency thereof, nor any of their employees, makes any warranty, express or implied, or assumes any legal liability or responsibility for the accuracy, completeness, or usefulness of any information, apparatus, product, or process disclosed, or represents that its use would not infringe privately owned rights. Reference herein to any specific commercial product, process, or service by trade name, trademark, manufacturer, or otherwise does not necessarily constitute or imply its endorsement, recommendation, or favoring by the United States Government or any agency thereof. The views and opinions of authors expressed herein do not necessarily state or reflect those of the United States Government or any agency thereof. 


\section{DISCLAIMER}

Portions of this document may be illegible electronic image products. Images are produced from the best available original document. 
the highest, whereas the beam life time after the stacking is the shortest. The Booster beam intensity after about $4 \mathrm{~ms}$ is slightly lower than in case B.

Because of the complication of the Booster injection process, the information obtained directly from Fig. 1 is limited. The factors that have influence on the Booster injection efficiency are numerous. These are:

1. Tandem beam profile, including transverse emittances, the momentum spread, etc.

2. The associated Tandem to Booster transfer line tuning.

3. Booster injection section, including the inflector, the injection kickers, the Booster equilibrium orbit at the inflector, etc.

4. Booster injection tuning, including the Booster tume, $x-y$ coupling, etc.
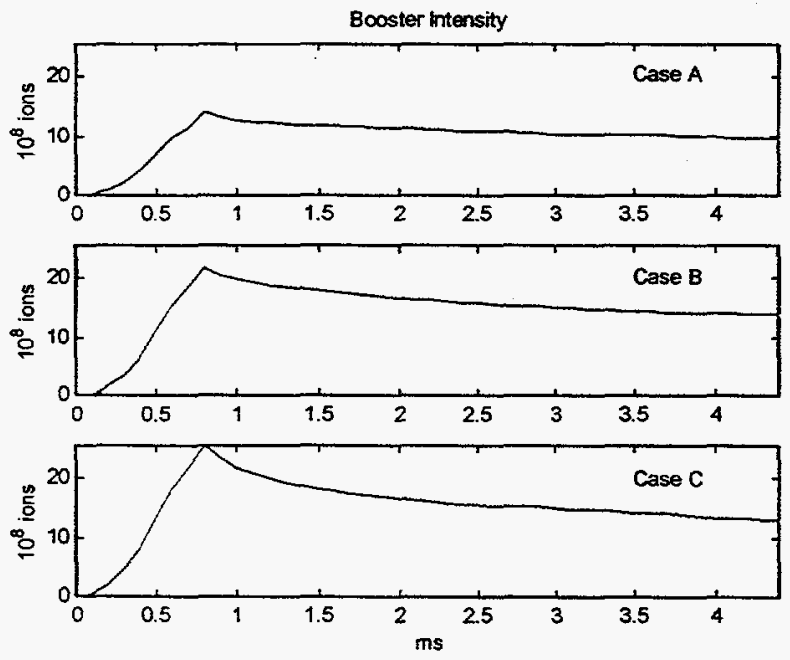

Fig.1

In addition, the large difference of the loss mechanism between the stacking and capturing also made the observation difficult to interpret.
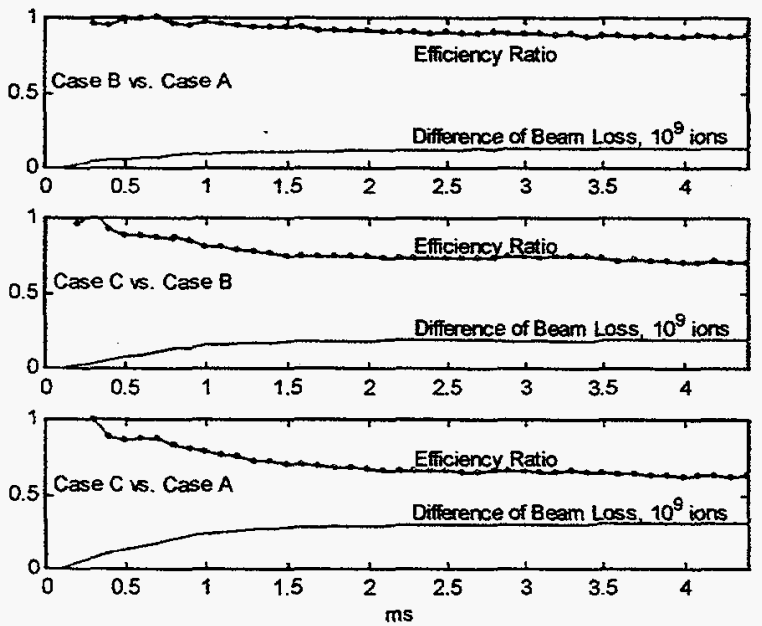

Fig.2
It is here assumed, however, that these factors had not been altered significantly during the period of study. Only minor resteering occurred. No significant emittance change was noted on multiwires in Tandem to Booster transfer line. Taking the Tandem beam intensity as the sole variable, its influence upon the injection efficiency can be singled out by the approach of comparison between the cases. To be specific, the efficiency ratio and the difference of the beam loss are used for examination.

The comparison of efficiency ratio and the difference of beam loss is shown in Fig. 2 for all cases. The single line represents the difference of the beam loss, and the line with small circles represents the efficiency ratio.

We have two observations,

1. In all cases, the efficiency ratio starts virtually from one at the low beam loss, it decreases in proportional to the increase of the difference of beam losses.

2. By using this approach of comparison, the transition of the beam loss mechanism from the stacking to the capturing, at $0.8 \mathrm{~ms}$, becomes very smooth.

The first observation suggests that the beam loss directly contribute to the decrease of Booster injection efficiency. This happened not only between the cases, but also with the entire injection process of each case, both at stacking and capturing.

The second observation shows further that the beam loss effect upon the Booster injection efficiency has indeed been singled out, despite the variation and transition of the beam loss mechanism during the injection period.

In an ideal injection, the beam loss would be zero, and the efficiency would be unity. In the approach we applied, i.e. to use the difference of beam loss and the efficiency ratio, the situation becomes simply the beam loss vs. efficiency.
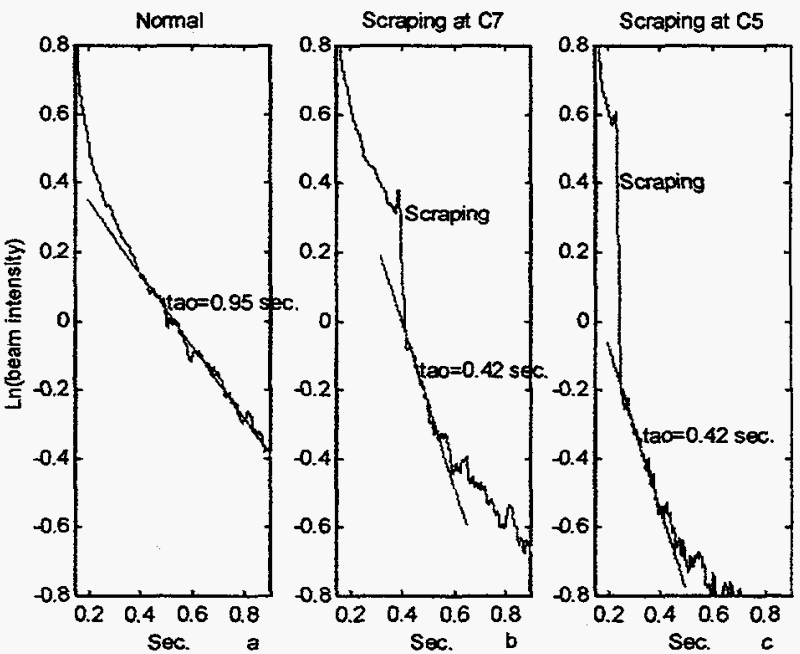

Fig.3

\section{Circulating Beam Scraping Study}

In the second experiment, a flat magnetic field a little higher than the injection energy is used to look at the 
beam life time. The beam is then scraped against the wall by 3 bumps systems. This is shown in Fig.3. In Fig.3a, it shows that the beam life time is about $950 \mathrm{~ms}$. In Fig.3b, the beam was scraped at the section $\mathrm{C} 7$ by vertical 3 bumps system. The beam life time after scraping becomes $420 \mathrm{~ms}$, though the intensity of circulating beam has been reduced. In Fig. $3 \mathrm{c}$, the beam was scraped at the section $C 5$. The scraped beam life time is also $420 \mathrm{~ms}$. Note, however, that the scraping happens at a different time than in case $3 b$.

The situation involved in this study is clear and simple. Issues such as the capture cross section variation and the RF capturing do not come up. The scraping is performed both vertically and horizontally, at several different places, the results are very similar.

Also a study has performed by cutting the intensity of the injected beam. By inserting multiwires in the Tandem to Booster transfer line, the injected beam intensity at the Booster is reduced by two third. The resulted beam life times in the Booster are not changed [3].

\section{Discussion}

The studies have shown that the beam life time, and the injection efficiency as well, are affected by the beam loss. It is assumed that the lost gold ion creates targets, that affect the life time of the circulating beam.

A close look has found that at the Booster injection, a lost $A u^{31+}$ ion creates about $10^{6}$ electrons [4]. This is because that $i$. The Booster gold beam injection energy happens to be at the highest production energy level for secondary electrons, ii. The production of secondary electrons is proportional to $q^{2}$, where $q$ is the charge state of projectile, and iii. The scraping effect - the lost gold ions hit the wall at extremely glancing angles.

A lost gold ion also creates large number of ions (mostly positive), and neutral particles, due to sputtering.

In 1998 heavy ion run, the production of positive ions and electrons due to the lost gold beam has been observed. Also the high vacuum pressure due to the beam loss, presumably because of the neutral particles it created, has been measured. The lost gold ion created high pressure could reach as high as $p=10^{-7}$ Torr, with about $10^{9}$ gold ions lost at the injection energy. The decay time of this pressure takes about $35 \mathrm{~ms}$, and the pressure 'bump' in ring is about 20 meters long. The details of these studies will be reported elsewhere.

\section{Reference}

1. C. Carlson and C. Gardner, private communication.

2. S.Y. Zhang and L.A. Ahrens, AGS Studies Report, No. 369, Feb. 1998.

3. L.A. Ahrens, AGS Studies Report, No. 354, Feb. 1997.

4. S.Y. Zhang, AGS Tech Note, No. 477, May, 1998. 